\title{
WILLINGNESS TO PAY FOR GREEN HOTELS IN BANGKOK, THAILAND
}

\author{
Kanyapilai Kunchornsirimongkon \\ Suan Sunandha Rajabhat University, Bangkok, Thailand \\ Morakot Ditta-Apichai \\ Songkhla Rajabhat University, Songkhla, Thailand
}

The purpose of this research has been to study the willingness to pay for accommodation in green hotels which are strictly following environmentally friendly policies. Questionnaire has been used as a tool to collect data from the people who stayed or have used other services of green hotels. In total, 385 guests in 19 Thai hotels have been surveyed. The results show that the willingness to pay for a green hotel was at a high level. People in Thailand are ready to choose a hotel that spends extra on environmentally friendly activities and/or environmentally friendly policies. In addition, our research has also found that sex, age and education level of consumers have a significant influence on the willingness to pay for green hotels. The results of this research can be beneficial for academic circles, hotel operators and marketing communicators promoting environmentally friendly hotel policies. Namely, our results can be used while developing marketing communications to attract consumers who are ready to choose green hotels.

Keywords: willingness to pay, green hotel, environmental friendly policy

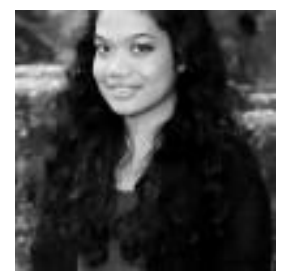

\section{Kanyapilai Kunchornsirimongkon}

MBA, lecturer in International College, Suan Sunandha Rajabhat University, Bangkok, Thailand

Research interests: hospitality, hotel management, international tourism market Published 12 papers in international journals

E-mail: kanyapilai.ku@ssru.ac.th

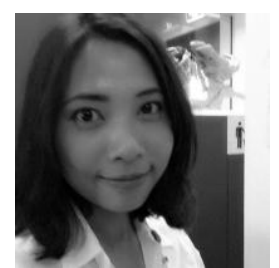

\section{Morakot Ditta-Apichai}

MBA, lecturer in Innovation and Management College, Songkhla Rajabhat University, Songkhla, Thailand

Research interests: entrepreneurship, digital business, service market

Published 7 papers in international journals

E-mail: morakot.di@skru.ac.th 


\section{WILLINGNESS TO PAY FOR GREEN HOTELS}

\section{Introduction}

Hospitality business plays an important role in part of income generation in tourism business of Thailand. Kasikorn Research Center (2018) reported the overall hotel business market value back in 2017 was worth 574,000 mln baht. It is likely to expand further, especially in Bangkok which is the most visited city in the country.

The number of visitors with accommodation in Bangkok (as of 2017) was 33,950,292 people. Of them, 20,575,172 were foreigners and 13,375,120 were local, Thai travelers. Together they have generated income in the amount of $947,284.30 \mathrm{mln}$ baht. This volume of this income category is continually growing (Ministry of Tourism and Sports, 2017). Expansion of hotel and other accommodation businesses is a vitally important factor for tourism growth in Thailand since hotels are serving the needs of both Thai and foreign tourists. Additionally, the growing size of the hospitality business has been increasing competition in this industry.

Therefore, hotel entrepreneurs are forced to improve all the time and to develop new strategies in order to maximize their competitive advantage and to provide services of higher quality. Becoming outstanding in services is the key to hotel business sustainability.

Global warming is causing higher world temperatures, changing the world environment, leading to more frequent natural disasters, solubility of polar ice, extinction of some animals, etc. For this reason, consumer behavior trends have been changing around the world with a tendency to consider various environmental issues more attentively. The hotel business is well aware of these changes in consumer behavior. Hotels have also started to pay more attention to environmentally friendly products and services.

As a result, hotels' clients are also more aware of the necessity to preserve the environment and treat natural resources more carefully (Han \& Kim, 2010). It is both necessary and interesting to study the real-life application of environmentally friendly policies in green hotels and in particular, the attitude of consumers towards the hotels with explicit eco-friendly policies. Certain variables are affecting the choice of those tourists who decide to stay in the environmentally friendly hotels (Rumpapak, 2018).

In hotel business operations, it is necessary to provide services that would focus on the convenience and satisfaction for those who are using services and products provided by a hotel. Therefore, a lot of energy, water and resources must be used (Robinot \& Giannelloni, 2010). As service processes, it causes various wastes which, directly and indirectly, affect the environment.

Thus, consumer environmental concerns may affect the decision while someone is choosing a hotel with an environmental policy. For this reason, various green projects have been already implemented under the hotels' green policies to protect the environment by saving water, energy, and waste reduction (Green Hotels Association, 2014).

Such green projects are needed among hotel guests increasingly (Kanchana, 2014). Moreover it demonstrated the willingness to pay to the hotels with such projects, both in the aspects of pleasure and readiness.

Thanawan \& Yupawan (2015) found that consumers' beliefs about environmentally friendly services have effect on their willingness to stay and use the service of green hotels. Also, good attitude of consumers affects the acceptance of uncomfortable conditions in exchange for environmental friendliness. This is consistent with the results obtained by Rahman and Raynold who stated that consumers are willing to sacrifice for maintaining the 
environment, and this directly affects the behavior of choosing environmentally friendly products and services.

Consumers with a positive perception of environmental friendliness are always willing to pay a higher price (Gronau \& Brohlburg, 2011; Rahman \& Raynold, 2016), but at the same time, some consumers might be hesitant to pay more (Han \& Chan, 2013).

Tourists do not want to pay extra money for eco-friendly hotels because they understand that green hotel room prices should be lower than the price in a regular hotel due to cost reduction caused by hotel green policy. In addition, both domestic and international research show that demographic factors can affect the willingness to pay. For example, Natdanai (2009) found that gender is a relative factor for such a willingness to pay. As a rule, females are more willing to pay for green products than males (Laroche et al. 2001).

Thus, we are interested here to study the willingness to pay among the guests who stay at green hotels in Thailand. In particular, we would like to research whether demographic characteristics have any influence on the willingness to pay for green hotels in Bangkok. Majority of studies on the hotel selection have been focusing on marketing mix, service quality, satisfaction, while hospitality research with an emphasis on the environmental issues is still at the infancy stage.

Therefore, new research on the willingness to pay for the services of green hotels and the factors affecting this willingness to pay would be beneficial for hotel entrepreneurs. Data, results and conclusions from this research can be used to develop marketing strategies in order to get attention and/or attract those tourists who are interested in hotels' environmental policy and base their stay on the availability of such policies.

\section{Objectives}

1. To study the willingness to pay for a green hotel within the population divided by certain parameters.

2. To study the influence of various population factors on the willingness to pay for a green hotel or an environmentally friendly hotel.

\section{Research Questions}

1. What levels can we determine in the willingness to pay for a green hotel?

2. What are the demographic differences that are affecting the willingness to pay for a green hotel?

\section{Hypotheses}

H1: Different genders have different levels of willingness to pay for green hotels.

$\mathrm{H} 2$ : People of different age have different levels of willingness to pay for green hotels.

H3: People with different marital status have different levels of willingness to pay for green hotels.

H4: Different levels of education lead to different levels of willingness to pay for green hotels. 


\section{WILLINGNESS TO PAY FOR GREEN HOTELS}

\section{Research scope}

The researcher has collected data from the customers who had some experience with staying in green hotels. To the best of our knowledge, there are at least 19 certified green hotels in Bangkok (Department of Environment Promotion, 2018). The sample group in this study included Thai citizens only.

\section{Methodology}

Our study is a quantitative research since it has been carried out using questionnaires as a key tool to survey Thai customers who experienced staying in green hotels. The researcher surveyed 385 people in total. Due to variety in demography (gender, age, marital status, education levels) the researcher chose quota sampling: in 19 Bangkok green hotels in total we have selected 20 people in each and then 1 was randomly selected in 5 large other hotels in order to get a complete sample of the specified amount.

Questionnaires have been used to collect personal data of those who stay or have used to stay and use the services of green hotels in Bangkok. The collected personal data included: gender, age, marital status, education level. Other questions were presented as a checklist since the questionnaire concerned the attitude and the willingness to pay for green hotel and eco friendly practices. Some of the questions were formulated using the rating scale with 5 levels, for example, the most, much, medium, less and the least. Data collection, data preparation and data analysis were carried out during June-August 2018.

\section{Results}

Section 1. General information \& demographic characteristics of the respondents

Table 1 presents general data on the 385 respondents classified by gender, age, marital status and educational level. It shows that the majority in the sample were female (195 persons), representing $50.6 \%$, while 190 males represented $49.4 \%$ of the sample.

The most popular age in our sample group is 35 years or older.

These were 203 people, or 52.7\%, followed by the age groups of 25-34 y.o., or 139 people, representing $36.1 \%$ of the sample. Respondents under 25 y.o. were 43 people, or $11.2 \%$, respectively.

Most of the respondents were married people - 270 people, or $70.1 \%$, followed by single people - 107 persons, or $27.8 \%$. Widowed or divorced, were 8 people only, accounting for $2.1 \%$.

The most widely spread education level within the sample was Bachelor's degree 263 people, or $68.3 \%$.

Bachelors were followed by people with full higher education (Masters, MBA or the equivalent) - 118 people, or $30.6 \%$. 4 people in the sample did not finish their undergraduate education ( $1.0 \%$ of the sample). 
Table 1 - Respondents classified by gender, age, marital status and education level (Source: made by co-authors)

\begin{tabular}{|c|c|c|}
\hline Demographic parameters & Amount & Percentage \\
\hline \multicolumn{3}{|l|}{ 1. Gender } \\
\hline - Male & 190 & 49.4 \\
\hline - Female & 195 & 50.6 \\
\hline \multicolumn{3}{|l|}{ 2. Age } \\
\hline -Younger than 25 & 43 & 11.2 \\
\hline - 25-34 y.o. & 139 & 36.1 \\
\hline$-35+$ y.o. & 203 & 52.7 \\
\hline \multicolumn{3}{|l|}{ 3. Marital Status } \\
\hline - Single & 107 & 27.8 \\
\hline - Married & 270 & 70.1 \\
\hline - Widowed/ Divorced & 8 & 2.1 \\
\hline \multicolumn{3}{|l|}{ 4. Education Level } \\
\hline - Below Bachelor & 4 & 1.0 \\
\hline - Bachelor & 263 & 68.3 \\
\hline - Higher than Bachelor & 118 & 30.6 \\
\hline Total & 385 & 100.0 \\
\hline
\end{tabular}

Section 2. Willingness to pay and the demography factors that influence it Tab. 2-7 show all further analytical data on the willingness to pay for green and/or environmentally friendly hotels along with the results of testing the hypotheses regarding the demographic factors that influence the willingness to pay for green hotels.

The information shown in Tab. 2 confirms that the overall willingness to pay for green hotel practices is at high level $(\bar{X}=3.42)$.

When considering the level of willingness to pay by items in the descending order, it has been found that the highest level belongs to paying for environmentally activities $(\bar{X}=$ 4.52 ), followed by "if there is a choice, you will choose to stay in a green hotel" ( $\bar{X}=4.35)$.

Then go the items with a moderate level of the willingness to pay: receiving more benefits than extra expenses for a green hotel $(\bar{X}=3.15)$, feeling proud to stay in a green hotel even though you pay more $(\bar{X}=3.09)$, the willingness to pay more for supporting environmentally friendly or green policy of a hotel $(\bar{X}=3.01)$.

The ranking ends with: all costs for green hotels are reasonable $(\bar{X}=2.92)$ and accepting the increased expenses for using the hotel's eco-friendly products and services $(\bar{X}$ $=2.90)$. 


\section{WILLINGNESS TO PAY FOR GREEN HOTELS}

Table 2 - Average and standard deviations in the level of willingness to pay among the guests of green hotels overall

(Source: made by co-authors)

\begin{tabular}{|l|c|c|c|c|}
\hline \multicolumn{1}{|c|}{ Willingness to pay for a green hotel } & $\bar{X}$ & SD & rank \\
\hline 1. If you have a choice, you will choose to stay in a green hotel & 4.35 & 0.759 & Most & 2 \\
\hline $\begin{array}{l}\text { 2. You are willing to pay more for supporting environmentally } \\
\text { friendly or green policy of a hotel }\end{array}$ & 3.01 & 0.741 & Medium & 5 \\
\hline $\begin{array}{l}\text { 3. You accept the increased expenses for using the hotel's eco- } \\
\text { friendly products and services }\end{array}$ & 2.90 & 0.654 & Medium & 7 \\
\hline $\begin{array}{l}\text { 4. You agree that you receive more benefits than just extra } \\
\text { expenses in a green hotel }\end{array}$ & 3.15 & 0.814 & Medium & 3 \\
\hline 5. You agree that green hotels' prices are reasonable & 2.92 & 0.668 & Medium & 6 \\
\hline $\begin{array}{l}\text { 6. Hotels should pay for their environmental activities } \\
\text { 7. You feel proud to stay in a green hotel even though you pay } \\
\text { more }\end{array}$ & 4.52 & 0.604 & Most & 1 \\
\hline Overall & 3.09 & 0.788 & Medium & 4 \\
\hline
\end{tabular}

Table 3 - The respondents' demographic data and the willingness to pay for green hotels / green practices by gender, age, marital status, and education level

(Source: made by co-authors)

\begin{tabular}{|c|c|c|c|c|c|}
\hline \multirow{2}{*}{ Demographics } & \multicolumn{4}{|c|}{ Willingness to pay more } & \multirow[t]{2}{*}{ Total } \\
\hline & $+10 \%$ & $+5 \%$ & $+2.5 \%$ & unwilling to pay & \\
\hline \multicolumn{6}{|c|}{ 1. Gender } \\
\hline - Male & $11(5.79 \%)$ & $24(12.63 \%)$ & $50(26.32 \%)$ & $105(55.26 \%)$ & $190(100 \%)$ \\
\hline - Female & $38(19.49 \%)$ & $58(29.74 \%)$ & $46(23.59 \%)$ & $53(27.18 \%)$ & $195(100 \%)$ \\
\hline \multicolumn{6}{|c|}{ 2. Age } \\
\hline - Younger that 25 & 0 & $27(62.79 \%)$ & 0 & $16(32.21 \%)$ & $43(100 \%)$ \\
\hline - 25-34 у.о. & 0 & $5(3.60 \%)$ & $1(0.72 \%)$ & $133(95.68 \%)$ & $139(100 \%)$ \\
\hline$-35+$ y.o. & $49(24.14 \%)$ & $50(24.63 \%)$ & $95(46.80 \%)$ & $9(4.43 \%)$ & $203(100 \%)$ \\
\hline \multicolumn{6}{|c|}{ 3. Marital status } \\
\hline - Single & $10(9.35 \%)$ & $27(25.23 \%)$ & $9(8.41 \%)$ & $61(57.01 \%)$ & $107(100 \%)$ \\
\hline - Married & $37(13.7 \%)$ & $52(19.26 \%)$ & $85(31.48 \%)$ & $96(35.56 \%)$ & $270(100 \%)$ \\
\hline - Widowed/Divorced & $2(25 \%)$ & $3(37.5 \%)$ & $2(25 \%)$ & $1(12.5 \%)$ & $8(100 \%)$ \\
\hline \multicolumn{6}{|c|}{ 4. Education Level } \\
\hline - Under bachelor & 0 & 0 & 0 & $4(100 \%)$ & $4(100 \%)$ \\
\hline - Bachelor & $19(7.22 \%)$ & $54(20.53 \%)$ & $61(23.19 \%)$ & $129(49.06 \%)$ & $263(100 \%)$ \\
\hline - Masters or higher & $30(25.43 \%)$ & $28(23.73 \%)$ & $35(29.66 \%)$ & $25(21.18 \%)$ & $118(100 \%)$ \\
\hline
\end{tabular}


Gender: The majority of male respondents (105 or $55.26 \%)$ are actually unwilling to pay more. They are followed by 50 males (or 26.32\%) who are willing to pay more, but only 2.5\%. 24 males (or 12.63\%) are willing to pay 5\% more, and only 11 male or $5.79 \%$ are ready to pay $10 \%$ more for a stay in a green hotel. $29.74 \%$ of female respondents are willing to pay $5 \%$ more, they are followed by those who are totally unwilling to pay more $(27.18 \%)$. 46 females or $23.59 \%$ are willing to pay the price which is $2.5 \%$ higher. And finally, 38 females or $19.49 \%$ are ready to pay $10 \%$ extra for a green hotel.

Age: More than half of the respondents who were younger than 25 y.o. $(62.79 \%$ of this age group) are willing to pay $5 \%$ more for a stay in a green hotel. They are followed by $37.21 \%$ of those who are totally unwilling to pay extra for a green hotel. Interestingly, nearly all the respondents aged 25-34 are absolutely not ready to pay more for a green hotel. At the same time, there are quite many of those who are willing to pay more are in the age group of 35 y.o. and above.

Marital status: Most of single people (61 of them) are not happy to pay extra for a green hotel. They are followed by the people willing to pay as much as 5\% extra - 27 people accounting, or $25.23 \%$. Then go those willing to pay $10 \%$ extra, 10 people only, or $9.35 \%$ and finally, those willing to pay $2.5 \%$ - 9 people, or $8.41 \%$. Moreover, 96 married people, or $35.56 \%$, were unwilling to pay extra for a green hotel as such. At the same time, 85 people, or $31.48 \%$, are willing to pay $2.5 \%$ extra, on the top of a regular price.

Education level: Guests with unfinished higher education (lower than Bachelor level) were unwilling to pay extra for a green hotel status, all $100 \%$ of them. 129 , or $49.06 \%$ of those with Bachelor level education, were unwilling to pay more. However, there were still 61 people, or $23.19 \%$, who stated they were willing to pay more for a green hotel, but no more than $2.5 \%$. Finally, 30 people, or $29.66 \%$ with Master degrees or higher, were willing to pay $2.5 \%$ more.

Table 4 - Guests' willingness to pay for green hotels split by gender (Source: made by co-authors)

\begin{tabular}{|c|c|c|c|c|}
\hline \multirow{2}{*}{ Demographics } & \multicolumn{4}{|c|}{ Willingness to pay for a green hotel } \\
\cline { 2 - 5 } & $\overline{\mathrm{X}}$ & S.D. & $\mathrm{t}$ & Sig. \\
\hline Gender & & & -4.529 & $0.000^{*}$ \\
Male & 3.28 & 0.612 & & \\
Female & 3.55 & 0.551 & & \\
\hline
\end{tabular}

* Statistical significance level of 0.05

The results (Tab. 4) of hypothesis testing by means of t-test show that gender difference in the willingness to pay for green hotels (tgender $=-4.529$, sig. $=0.002$ ) is statistically significant at the .05 level. In simple terms, female guests are generally more willing to pay for green policies than male guests.

The results of hypothesis testing by means of using the one-way ANOVA to test $\mathrm{H} 2$ $\mathrm{H} 4$ show that age and education level differences affect the willingness to pay for green policies of green hotels in different dimensions (Fage $=351.374$; Feducation $=10.558$, sig. $=$ 0.000). At the same time, differences in the marital status do not affect the willingness to pay for the eco-friendly policy of hotels (Fmarital $=2.698$, sig. $=0.069$ ). Further testing of differences in the willingness to pay for environmentally friendly policies across different 


\section{WILLINGNESS TO PAY FOR GREEN HOTELS}

age groups and education levels has been carried out using LSD. The results are shown in Tab. 6 and 7.

Table 5 - Guests' willingness to pay for green hotels, by age, marital status and education level

(Source: made by co-authors)

\begin{tabular}{|c|c|c|c|c|c|c|}
\hline \multirow{2}{*}{ Demographics } & \multicolumn{6}{|c|}{ Willingness to pay more } \\
\hline & Variance & $\mathrm{SS}$ & $\mathrm{df}$ & MS & $\mathrm{F}$ & Sig. \\
\hline \multicolumn{5}{|c|}{ Age } & \multirow[t]{4}{*}{351.374} & \multirow[t]{4}{*}{$0.000 *$} \\
\hline & between group & 88.484 & 2 & 44.242 & & \\
\hline & within group & 48.098 & 382 & 0.126 & & \\
\hline & total & 136.582 & 384 & & & \\
\hline \multicolumn{5}{|c|}{ Marital status } & \multirow[t]{4}{*}{2.698} & \multirow[t]{4}{*}{0.069} \\
\hline & between group & 1.902 & 2 & 0.951 & & \\
\hline & within group & 134.679 & 382 & 0.353 & & \\
\hline & total & 136.582 & 384 & & & \\
\hline \multicolumn{5}{|c|}{ Education } & \multirow[t]{4}{*}{10.558} & \multirow[t]{4}{*}{$0.000 *$} \\
\hline & between & 7.154 & 2 & 3.577 & & \\
\hline & within group & 129.427 & 382 & 0.339 & & \\
\hline & total & 136.582 & 384 & & & \\
\hline
\end{tabular}

* Statistical significance level of 0.05

Table 6 - Comparison of the willingness to pay classified by age, LSD

(Source: made by co-authors)

\begin{tabular}{|l|c|c|c|c|}
\hline \multirow{2}{*}{ Age } & $\bar{X}$ & Younger than 25 & $25-34$ y.o. & $35+$ y.o. \\
\cline { 3 - 5 } & & 4.14 & 2.81 & 3.69 \\
\hline Younger than 25 & 4.14 & - & $1.33^{*}$ & $0.45^{*}$ \\
\hline 25-34 y.o. & 2.81 & & - & $-0.88^{*}$ \\
\hline 35+ y.o. & 3.69 & & & - \\
\hline
\end{tabular}

* Statistical significance level of 0.05

Table 7 - Comparison of the willingness to pay classified by education levels, LSD method (Source: made by co-authors)

\begin{tabular}{|l|l|l|l|l|}
\hline \multirow{2}{*}{ Education level } & $\overline{\mathrm{X}}$ & $\begin{array}{l}\text { Under Bachelor } \\
\text { degree }\end{array}$ & $\begin{array}{l}\text { Bachelor } \\
\text { degree }\end{array}$ & $\begin{array}{l}\text { Master degree } \\
\text { or higher }\end{array}$ \\
\cline { 3 - 5 } & 2.39 & 3.37 & 3.56 \\
\hline under Bachelor degree & 2.39 & - & $-0.98^{*}$ & $-1.17^{*}$ \\
\hline Bachelor degree & 3.37 & & - & $-0.19^{*}$ \\
\hline Master degree or higher & 3.56 & & & - \\
\hline
\end{tabular}

* Statistical significance level of 0.05

In Tab. 6, the comparison by means of LSD shows that guests under 25 have higher than average willingness to pay for green hotels overall. Guests aged 25-34 yo and also those aged $35+$ yo demonstrate the statistical significance at the level of 0.05 , with the average 
difference of 1.33 and 0.45 , respectively. Also, guests aged $35+$ have more willingness to pay for an introduced in a hotel environmental policy rather than guests within the 25-34 yo age group, with the average difference of 0.88 .

The results of LSD (Tab. 7) demonstrate that guests with education below Bachelor have an average willingness to pay for eco-friendly policies which is less than those of the guests with a Bachelor or higher degree, at the significance level of 0.05 . The difference was at the level of 0.98 and 1.17 , respectively.

The guests with higher than Bachelor education had the average attitude to green policies of hotels higher than the attitude of those with a Bachelor degree, with the statistical significance at the level of 0.05 and the mean difference of 0.19 .

\section{Discussion}

According to our findings, the willingness to pay for green practices of hotels in Thailand is, generally speaking, rather high. Overall, people will choose to stay at the hotels that are environmentally friendly because they see that these extra money paid will be spent on protecting the environment. This result is consistent with the research results of Gronau \& Brohlburg (2011) and also those of Rahman \& Raynold (2016). Both these teams of authors have found that consumers are willing to pay more if there are environmental operations in green hotels.

Demographic factors influence the guests' willingness to pay for green hotels. Female guests are generally more willing to pay for green hotel policies as opposed to male guests. This conclusion is consistent with the research results of (Laroche, et al., 2001).

These authors have also found that $57 \%$ of females are willing to pay more for green products, and this percentage is significantly higher than that of males. This confirms that women generally pay more attention to environmental issues as opposed to males.

Moreover, age is another factor that affects the willingness to pay for a stay in a green hotel. Guests under 25 are willing to pay more for environmentally friendly hotels than people of other age groups. This result is very similar to the one obtained by Pattamrangsan (2016) who also mentioned that age affects the willingness of paying among the visitors of the Royal Rajapruek Park.

Most probably, this may be because the youth is now more aware about the world's environmental problems (Moodie et al., 2011). Therefore, their behavior of choosing to stay in an environmentally friendly hotel is affected by this awareness.

The guests' education levels also affect the willingness to pay. More specifically, those with a Bachelor education are willing to pay extra for hotels' green policies more than those with lower education. This may be due to the fact that higher education is often resulting in wider exposure to international news and other information. Thus, awareness of environmental problems gets higher. People with higher education tend to recognize the importance of environment protection.

Thus, they also demonstrate more willingness to pay extra for a stay in a hotel that actively introduces and supports environmentally friendly policies.

This author has found that different education levels among the staff members of Dusit Thani Hotel lead to differences in attitudes and engagement in preserving the hotel environment. Finally, this study has found that marital status does not influence the willingness to pay for a stay in green hotels. 


\section{WILLINGNESS TO PAY FOR GREEN HOTELS}

\section{Suggestion}

1. This study shows that people's willingness to pay for environmentally friendly products and services of hotels is overall quite high. In our view, hotel owners and hotel managers should study this area more so that better understand what is reasonable accommodation pricing for a green hotel.

2. Hotel entrepreneurs should apply green policies more actively. In terms of marketing, green policies should be targeting females, people with higher education and also teenager tourists. These audiences, at least in Thailand, demonstrate the highest willingness to pay for green products and services as compared to other social and economic groups.

\section{Directions for Future Studies}

1. Once the green policies have been fully introduced by more hotels in Thailand, other studies should be carried out with the aim to evaluate the satisfaction level among the guests of such hotels. Namely, factors behind this satisfaction should be determined.

2. This topic is actually also applicable to other business sectors as well, for example, private hospitals. Since increasing many people are coming to Thailand with the purposes of the so-called medical tourism, they become not only hotel guests but also hospital visitors. Thus, hospitals might be interested in the introduction of green policies as well.

\section{References:}

Pattamrangsan, C. (2016) Willingness to pay the entrance fee of visitors to the Royal Park Rajapruek Chiangmai Province. Chiang Mai University.

Department of Environmental Quality (2018). List of certified friendly and environmental hotels. Bangkok press.

Green Hotels Association (2014). What Are Green Hotels. Kasetsart University, Bangkok.

Gronau, W. \& Brohlburg, L. (2011). Green Hotels a New Strategy for the Mass Market? A Consumer Study from Cyprus. In: Kagermeier, A. \& Reeh, T. (Eds): Trends, Herausforderungen und Perspektiven für die Tourismus geographische Forschung. Mannheim: MetaGis.

Han, H. \& Kim, Y. (2010). An investigation of green hotel customers' decision formation: Developing an extended model of the theory of planned behavior. International Journal of Hospitality Management, 29(4), 659-668.

Han, X. \& Chan, K. (2013). Perception of Green Hotels Among Tourists in Hong Kong: An Exploratory Study. Services Marketing Quarterly, 34(4), 339-352.

Kanchana, S. (2014). Study on the willingness to pay for green hotels. Bangkok: Thailand Research Fund.

Kasikorn Thai Research Centre (2018). Competition and Adaptation of Hotel Business. Available online at: https://www.kasikornbank.com/th/business/sme/

Laroche, M., Bergeron, J. \& Barbaro-Forleo, G. (2001). Targeting consumers who are willing to pay more for environmentally friendly products. The Journal of Consumer Marketing, 18(6), 503520 . 
Ministry of Tourism and Sport (2017). Domestic Tourism Statistic 2017. Available at: https://www.mots.go.th/more_news.php?cid=504\&filename=index

Moodie, C., Ford, A., Mackintosh, A.M. \& Hastings, G., (2011). Young people's perceptions of cigarette packaging and plain packaging: an online survey. Nicotine \& Tobacco Research, 14(1), 98-105.

Natthadanai, S. (2009). A study of the value of utilization and the willingness to pay fees: a case study of Subdistrict Nakhon Sri Thammarat. Kasetsart University, Bangkok.

Rahman, I. \& Reynolds, D. (2016). Predicting green hotel behavioral intentions using a theory of environmental commitment and sacrifice for the environment. International Journal of Hospitality Management, 52, 107-116.

Robinot, E. \& Giannelloni, J. (2010). Do hotels "Green" attributes contribute to customer satisfaction? Journal of Services Marketing, 24(2), 157-169.

Rumpapak, L. (2018). Key factors affecting tourists' decisions to stay at Environmental Friendly Hotels. Polish Journal of Management Studies, 17 (2), 148-157.

Thanawan, M. \& Yupaworn, W. (2015). Customers' attitudes affecting the intention to stay and use the services of green hotels. Dusit Thani Journal, 9(1), 37-49.

Paper submitted

Paper accepted for publishing

Paper published online
11 June 2020

02 September 2020

30 September 2020 